\title{
ANALISIS KESALAHAN KEEFEKTIFAN KALIMAT PADA TEKS BIOGRAFI KARANGAN SISWA KELAS VIII SMP NEGERI 158 JAKARTA
}

\author{
Putri Setya Nur Utami \\ SMP Negeri 158 Jakarta \\ pusenut@gmail.com
}

\begin{abstract}
ABSTRAK
Penelitian ini bertujuan untuk mendeskripsikan kesalahan keefektifan kalimat. Metode yang digunakan dalam penelitian ini adalah deskriptif kualitatif dengan teknik analisis isi. Fokus penelitian ini yaitu keefektifan kalimat berdasarkan unsur kegramatikalannya. Objek penelitian ini dilakukan pada teks biografi karangan siswa kelas VIII SMP Negeri 158 Jakarta, dengan jumlah karangan sebanyak 30 teks biografi. Berdasarkan hasil penelitian, ditemukan sebanyak 70 kesalahan, yaitu: 8 kesalahan pada urutan dasar, 7 kesalahan pada urutan variasi, 27 kesalahan pada peniadaan unsur, 12 kesalahan pada kesejajaran, 16 kesalahan pada penggunaan konjungsi. Maka dapat disimpulkan bahwa, kesalahan keefektifan kalimat pada siswa kelas VIII dalam teks biografi masih banyak terjadi. Hal ini disebabkan oleh karakteristik siswa kelas VIII yang belum memahami keefektifan kalimat berdasarkan unsur kegramatikalannya secara mendalam, sehingga penggunaan keefektifan kalimat berdasarkan unsur kegramatikalannya belum tepat. Implikasi terhadap pembelajaran Bahasa Indonesia, yaitu pada Kurikulum 2013 KD 3.3 mengklasifikasi tesk cerita moral atau fabel, ulasan, diskusi, cerita prosedur, dan cerita biografi baik melalui lisan maupun tulisan. 4.3 menelaah dan merevisi teks cerita moral atau fabel ulasan, diskusi, cerita prosedur, dan cerita biografi baik melalui lisan maupun tulisan. Dengan demikian, siswa dapat menulis karangan teks biografi dengan kaidah kebahasaan yang lebih baik, terlebih dalam penggunaan keefektifan kalimat berdasarkan unsur kegramatikalannya.
\end{abstract}

Kata kunci: analisis kesalahan, keefektifan kalimat, teks biografi 


\title{
ANALYSIS OF THE EFFECT OF THE EFFECTIVENESS OF SENTENCE IN THE TEXT BIOGRAPHIC TEXT OF CLASS VIII STUDENTS SMP NEGERI 158 JAKARTA
}

\begin{abstract}
This study aims to describe the error of sentence effectiveness. The method used in this study is descriptive qualitative with content analysis techniques. The focus of this research is the effectiveness of sentences based on the kegramatikalan elements. The object of this research was carried out on biographical texts written by class VIII students SMP Negeri 158 Jakarta, with a total of 30 biographical texts. Based on the results of the study, there were 70 errors, namely: 8 errors in the base sequence, 7 errors in the order of variation, 27 errors in elimination of elements, 12 errors in alignment, 16 errors in the use of conjunctions. So it can be concluded that, the errors in the effectiveness of sentences in class VIII students in biographical texts still occur a lot. This is due to the characteristics of class VIII students who have not understood the effectiveness of sentences based on their kegramatikalan elements in depth, so that the use of sentence effectiveness based on the kegramatikalan element is not appropriate. The implications of learning Indonesian language, namely in the 2013 Curriculum KD 3.3 classifies the tests of moral or fable stories, reviews, discussions, procedure stories, and biographical stories both through oral and written. 4.3 examines and revises moral story texts or fable reviews, discussions, procedure stories, and biographical stories both through oral and written. Thus, students can write biography text essays with better linguistic rules, especially in the use of sentence effectiveness based on the kegramatikalan elements.
\end{abstract}

Keywords: error analysis, effectiveness of sentences, biographical texts

\section{PENDAHULUAN}

Keterampilan berbahasa merupakan kemampuan seseorang yang meliputi keterampilan berbicara, keterampilan menyimak, keterampilan membaca, dan keterampilan menulis. Keterampilan menyimak dan keterampilan berbicara masuk ke 
dalam ragam bahasa lisan (Chaer, 2012). Sementara itu, keterampilan membaca dan menulis masuk ke dalam ragam bahasa tulis.

Keterampilan menulis merupakan kemampuan seseorang yang berhubungan dengan kata-kata, kalimat-kalimat, pengembangan, dan menuangkan pikiran-pikiran ke dalam suatu tulisan yang berstruktur (Mahsun, 2014). Sebuah tulisan dikatakan baik apabila memenuhi syarat-syarat sebagai berikut: (1) kemampuan untuk menemukan masalah yang akan ditulis (2) kepekaan terhadap kondisi pembaca (3) kemampuan menyusun rencana penulisan (4) kemampuan menggunakan bahasa (5) kemampuan memulai tulisan (6) kemampuan memeriksa tulisan. Menulis adalah kegiatan komunikasi berupa penyampaian pesan secara tertulis kepada pihak lain. Dalam menyampaikan makna dan tujuan dibutuhkan penggunaan bahasa yang benar, seperti yang telah dikatakan sebelumnya bahwa salah satu syarat penulisan yang baik yaitu kemampuan menggunakan bahasa. Penggunaan bahasa yang benar tergambar dalam penggunaan kalimat-kalimat yang gramatikal, yaitu kalimat-kalimat yang memenuhi kaidah tata bunyi, tata bahasa, kosa kata, istilah, dan ejaan baik (Mustakim, 1994). Selain itu dibutuhkan pula struktur kalimat yang. Kalimat yang baik haruslah memenuhi persyaratan gramatikal (Utami, 2017). Hal tersebut akan lebih memudahkan para pembaca karangan teks tersebut dalam memahami makna yang akan disampaikan di dalam teks karangan tersebut. Berikut beberapa contoh kalimat dalam teks:

Contoh kalimat 1:

(1) Di dalam kontrak kerja membicarakan jadwal dan honor.

Di dalam kontrak kerja (K)membicarakan $(\mathrm{P})$ jadwal dan honor $(\mathrm{O})$

AKSIS Jurnal Pendidikan Bahasa dan Sastra Indonesia

Volume 2 Nomor 2, Desember 2018 e-ISSN: 2580-9040

e-Journal: http://doi.org/10.21009/AKSIS 
mengandung pola K-P-O. Kalimat tersebut tidak mengandung fungsi subjek, karena kalimat fungsi subjek dilesapkan setelah fungsi keteranngan, sehingga kalimat tersebut tidak mengandung informasi mengenai pelaku, tempat subjek menjadi kosong. Kalimat tersebut dapat dijadikan kalimat efektif apabila fungsi subjek setelah fungsi keterangan. Dengan demikian perbaikan kalimat tersebut sebagai berikut:

(1a) Di dalam kontrak kerja (K) Dia (S) membicarakan (P) jadwal dan honor (O)

Contoh kalimat 2:

\section{(2) Dengan kemenangan regu Indonesia membutikan bahwa bintang-} binntang sepak bola berada di negeri kita.

Dengan kemenangan regu Indonesia $(\mathrm{K})$ membutikan $(\mathrm{P})$ bahwa bintang-bintang sepak bola $(\mathrm{O})$ berada di negeri kita. $(\mathrm{K})$

Pada kalimat “dengan kemenangan regu Indonesia membutikan bahwa

bintang-bintang sepak bola berada di negeri kita." mengandung pola K-P-O-K. Kalimat tersebut tidak mengandung fungsi subjek, karena kalimat fungsi subjek dilesapkan setelah fungsi keteranngan, sehingga kalimat tersebut tidak mengandung informasi mengenai pelaku, tempat subjek menjadi kosong. Kalimat tersebut dapat dijadikan kalimat efektif apabila fungsi subjek setelah fungsi keterangan. Dengan demikian perbaikan kalimat tersebut sebagai berikut:

AKSIS Jurnal Pendidikan Bahasa dan Sastra Indonesia

Volume 2 Nomor 2, Desember 2018 e-ISSN: 2580-9040

e-Journal: http://doi.org/10.21009/AKSIS 
(2a) Dengan kemenangan regu Indonesia (K) mereka (S) membuktikan (P) bahwa bintang-bintang sepak bola $(\mathrm{O})$ berada di negeri kita. $(\mathrm{K})$

Contoh kalimat 3:

(3) Agnes Monica Muljoto atau biasa disapa Agnes Monica, dilahirkan di Jakarta pada tanggal 1 Juli 1985, dia merupakan anak bungsu bungsu dari pasangan Jenny Siswono dan Ricky Suprapto, dia memiliki seorang kakak lakilaki bernama Steve Muljoto yang kemudian menjadi managernya.

Pada kalimat di atas, memiliki tiga subjek, dan tiga predikat. Agnes pada kalimat pertama memiiki fungsi sebagai (S) untuk kalimat pertama. Dia pada kalimat kedua memiliki fungsi (S) untuk kalimat kedua, kemudian dia pada kalimat ketiga juga memiliki fungsi (S) untuk kalimat ketiga. Dengan demikian kalimat tersebut tidak memiliki kesalahan, hanya saja terdapat tiga kalimat tunggal, karena masing-masing kalimat berperan sebagai kalimat tunggal yang memiliki tiga subjek.

Berdasarkan penjelasan di atas, dapat kita simpulkan bahwa penulisan kalimat dengan struktur gramatikal yang baik sangat menentukan efektif atau tidaknya kalimat yang akan dituangkan ke dalam teks. Keterampilan menulis akan menghasilkan berbagai macam ragam bahasa tulis, salah satunya karangan teks biografi. Seperti yang tercantum dalam Kurikulum 2013 KD 3.3 Mengklasifikasi tek cerita moral/fabel, ulasan, diskusi, cerita prosedur, dan cerita biografi baik melalui lisan maupun tulisan. 4.3 Menelaah dan merevisi teks cerita moral/fabel ulasan, diskusi, cerita prosedur, dan cerita biografi baik melalui lisan maupun tulisan. Peserta didik diminta untuk memahami dan siswa mampu menulis sebuah karangan teks biografi. Oleh karena itu, 
berdasarkan uraian yang telah disebutkan di atas, penulis tertarik untuk melakukan penelitian yang memiliki hubungan dengan analisis kesalahan keefektifan kalimat untuk mengetahui kesalahan keefektifan kalimat yang terjadi di kalangan siswa dalam penulisan sebuah teks karangan biografi, dengan tujuan untuk mengetahui bagaimana kesalahan keefektifan kalimat yang terjadi dalam penulisan sebuah teks karangan biografi yang dibuat oleh siswa. Penelitian kali ini dilakukan terhadap siswa Sekolah Menengah Pertama 158 Jakarta dengan fokus penelitian keefektifan kalimat berdasarkan unsur kegramatikalannya, dan penelitian ini bertujuan untuk mendeskripsikan kesalahan yang terjadi. Berdasarkan ulasan tersebut, maka akan dilakukan penelitian dengan judul "Analisis Kesalahan Keefektifan Kalimat pada Teks Biografi Karangan Siswa Kelas VIII SMPN 158 Jakarta”.

\section{METODE}

Penelitian ini bertujuan untuk mendeskripsikan kesalahan keefektifan kalimat berdasarkan unsur kegramatikalannya pada teks biografi karangan siswa kealas VIII SMPN 158 Jakarta. Metode yang digunakan dalam penelitian ini adalah deskriptif kualitatif dengan teknik analisis isi.

Persepsi awal pada penelitian ini adalah bahwa tak jarang terjadi kesalahan keefektifan kalimat yang dilakukan oleh siswa kelas VIII SMPN 158 Jakarta dalam penyusunan kalimat terlebih berdasarkan unsur kegramatikalannya. Penelitian ini dilakukan dengan pengambilan 30 teks biografi karangan siswa pada bulah Maret sampai dengan bulan April. Setelah mendapatkan kelas yang cocok untuk melakukan 
penelitian, selanjutnya masuk ke dalam kelas guna meminta siswa untuk membuat satu karangan teks biografi. Hasil teks biografi karangan siswa tersebut dianalisis oleh peneliti, kemudian ditentukan kesalahannya berdasarkan bagian yang cocok.

\section{HASIL DAN PEMBAHASAN}

Penulisan sebuah teks biografi harus sesuai dengan kaidah kebahasaan terlebih unsur kegramatikalannya harus benar. Dengan demikian itu akan membuat hasil karangan teks biografi menjadi lebih menarik untuk dibaca, juga akan lebih memudahkan untuk penyampaian pesan dan tujuan dalam teks biografi tersebut.

Tabel 4.1 Rekapitulasi Data Kesalahan Keefektifan Kalimat pada Teks Biografi

$$
\text { Karangan Siswa Kelas VIII SMPN } 158 \text { Jakarta }
$$

\begin{tabular}{|c|c|c|c|}
\hline \multicolumn{2}{|c|}{ Kesalahan Keefektifan Kalimat } & Banyaknya & Persentase \\
\hline \multirow{3}{*}{ Struktur } & Urutan Dasar & 8 & $11,4 \%$ \\
\cline { 2 - 4 } & Urutan Variasi & 7 & $10 \%$ \\
\hline Perluasan & Penambahan Unsur & 0 & $0 \%$ \\
& Peniadaan Unsur & 27 & $38,6 \%$ \\
\cline { 2 - 4 } & Kesejajaran & 12 & $17,2 \%$ \\
\hline \multirow{2}{*}{ Kemandirian } & 0 & $0 \%$ \\
\hline & Konjungsi & 16 & $22,8 \%$ \\
\hline & Total Data & $\mathbf{7 0}$ & $\mathbf{1 0 0 \%}$ \\
\hline
\end{tabular}

AKSIS Jurnal Pendidikan Bahasa dan Sastra Indonesia

Volume 2 Nomor 2, Desember 2018 e-ISSN: 2580-9040 
Berbicara mengenai unsur kegramatikalan bahasa, teks biografi membutuhkan unsur kegramatikalan dalam penulisannya. Seperti karangan teks biografi yang ditulis oleh siswa kelas VIII SMPN 158 Jakarta. Dalam teks biografi yang telah ditulis oleh siswa kelas VIII SMPN 158 Jakarta, terdapat 70 kesalahan keefektifan kalimat dari unsur kegramatikalannya. Dari ke-70 kesalahan keefektifan kalimat dalam teks biografi tersebut, ditemukan 8 kesalahan keefektifan kalimat pada struktur urutan dasar, 7 kesalahan keefektifan kalimat pada urutan variasi, 27 peniadaan unsur subjek, 12 kesalahan keefektifan kalimat pada kesejajaran, dan 16 kesalahan keefektifan kalimat pada konjungsi.

Unsur-unsur kegramatikalan digunakan sebagai alat bedah apakah kalimat yang ditulis sudah memenuhi kaidah kebahasan yang benar atau tidak. Berikut adalah data dan analisis kesalahan keefektifan kalimat berdasarkan unsur kegramatikalannya:

\section{Urutan Dasar}

\section{Meninggal pada saat puncak popularitas.}

\section{Meninggal (P) pada saat puncak popularitas.(K)}

Pada kalimat tersebut memiliki pola P-K. Dengan demikian subjek pada kalimat tersebut tidak ditemukan. Hal ini agar kalimat tersebut gramatikal, pola subjek dapat dieksplisitkan sebelum pola predikat, menjadi (Nike Ardilla) meninggal pada saat puncak popularitas. 


\section{Variasi Urutan}

\section{Album lagu dia tidak pernah membuat.}

\section{Album lagu (O) dia (S) tidak pernah membuat.(P)}

Berdasarkan kalimat di atas, diketahui bahwa pola kalimat tersebut ialah O-S-P, sedangkan menurut teori Dendy Sugono struktur kalimat pada urutan variasi yaitu kalimat-kalimat yang memiliki pola P-O-K-S/P-O-Pel-S/P-O-S/P-Pel-S/P-S/ P-S/K-PS/K-S-P/K-P-S/P-S-K/P-S/P-K-S. Dengan demikian, kalimat tersebut mengalami kesalahan keefektifan kalimat dari unsur gramatikal pada urutan dasar kalimat. Maka dari itu, agar kalimat tersebut memenuhi unsur gramatikal, kalimat di atas dapat diubah polanya menjadi:

\section{Dia tidak pernah membuat album lagu.}

3) Peniadaan Unsur

\section{Di rumah memikirkan novel.}

Di rumah (K) memikirkan (P) novel.(O)

Berdasarkan kalimat di atas, diketahui bahwa pola Kalimat itu memiliki unsur K-(S)-P-O. Dengan demikian, kalimat tersebut tidak memenuhi unsur gramatikal, karena subjek dilesapkan antara keterangan dengan predikat. Untuk itu timbul pertanyaan siapa yang memikirkan novel (sebagai subjek dalam kalimat tersebut). Hal 
ini agar kalimat tersebut gramatikal, pola subjek dapat dieksplisitkan setelah pola keterangan.

Di rumah (S=dieksplisitkan) memikirkan novel.

\section{Kesejajaran}

Tulisan itu dilihat masyarakat, lalu orang-orang membeli tulisan tersebut.

Berdasarkan kalimat di atas, diketahui bahwa kalimat itu menggunakan predikat verba pasif pada kalimat tunggal pertama, sedangkan menggunakan predikat verba aktif pada kalimat tunggal kedua. Sementara itu menurut teori Dendy Sugono, apabila kalimat dasar pertama sudah menggunakan verba aktif, maka pada kalimat dasar kedua juga harus menggunakan verba aktif. Sebaliknya, apabila pada kalimat dasar pertama sudah menggunakan verba pasif, maka pada kalimat dasar kedua juga harus menggunakan verba pasif. Dengan demikian terjadi kesalahan keefektifan kalimat pada kalimat tersebut. Hal ini agar kalimat tersebut memenuhi unsur gramatikal, kalimat di atas dapat diubah menjadi:

Tulisan itu dilihat masyarakat, lalu tulisan tersebut dibeli oleh orang-orang.

\section{Konjungsi}

Walaupun Budi Darma dinobatkan sebagai warga berprestasi, tetapi beliau tidak pernah merasa dirinya sosok yang hebat. 
Berdasarkan kalimat di atas, diketahui bahwa kalimat itu memiliki dua konjungsi sehingga membuat kedua kalimat dasar dalam kalimat majemuk itu berfungsi sebagai anak kalimat, hal itu berarti bahwa kalimat majemuk tersebut tidak memiliki induk kalimat sebagai gagasan pokok. Dengan demikian, terjadi kesalahan keefektifan kalimat pada kalimat tersebut. Hal ini agar kalimat tersebut memenuhi unsur gramatikal, kalimat di atas dapat diubah menjadi:

Walaupun Budi Darma diinobatkan sebagai warga berprestasi, beliau tidak pernah merasa dirinya sosok yang hebat. Atau

Budi Darma diinobatkan sebagai warga berprestasi, tetapi beliau tidak pernah merasa dirinya sosok yang hebat.

\section{KESIMPULAN}

Berdasarkan tabel di atas, terdapat kesalahan keefektifan kalimat berdasarkan unsur kegramatikalannya. Keefektifan kalimat berdasarkan unsur kegramatikalannya tersebut terbagi menjadi lima, yaitu struktur kalimat, perluasan, kesejajaran, kemandirian, dan konjungsi. Struktur kalimat dibagi lagi menjadi dua bagian yaitu urutan dasar kalimat dan urutan variasi kalimat. Begitu juga dengan perluasan unsur, dibagi menjadi penambahan unsur dan peniadaan unsur. Berdasarkan uraian di atas, dapat disimpulkan bahwa kesalahan keefektifan kalimat yang paling banyak ditemukan yaitu kesalahan pada peniadaan unsur dengan 27 kesalahan, peringkat kedua yaitu kesalahan pada urutan dasar kalimat dengan 18 kesalahan, peringkat ketiga yaitu 
kesalahan pada konjungsi kalimat sebanyak 16 kesalahan, peringkat keempat yaitu kesalahan pada kesejajaran sebanyak 12 kesalahan, peringkat kelima yaitu kesalahan pada urutan variasi kalimat sebanyak 7 kesalahan. Sementara kesalahan pada penambahan unsur dan kemandirian tidak ditemukan sama sekali dalam teks biografi karangan siswa kelas VIII SMPN 158 Jakarta.

\section{UCAPAN TERIMA KASIH}

Terima kasih saya ucapkan kepada Ibu Sintowati Rini Utami, M.Pd. Ibu N. Lia Marliana, M.Phil (Ling) yang telah membimbing dan memberi masukan untuk penelitian ini.

\section{DAFTAR PUSTAKA}

Chaer, Abdul. (2012). Linguistik Umum. Jakarta: Rineka Cipta.

Mahsun. (2014). Teks dalam Pembalajaran Bahasa Indonesia Kurikulu 2017. Depok: Rajagrafindo Persada.

Mulya, et.al. (2017). Pembelajaran Menulis Teks Biografi. Bandar Lampung: Global.

Mustakim. 1994. Membina Kemampuan Berbahasa Panduan Ke Arah Kemahiran Berbahasa. Jakarta: Gramedia Pustaka Utama.

Utami, S. R. (2017). Pembelajaran Aspek Tata Bahasa dalam Buku Pelajaran Bahasa Indonesia. Aksis: Jurnal Pendidikan Bahasa dan Sastra Indonesia, 1(2). 189203. doi: doi.org/10.21009/AKSIS.010203

AKSIS Jurnal Pendidikan Bahasa dan Sastra Indonesia

Volume 2 Nomor 2, Desember 2018 e-ISSN: 2580-9040

e-Journal: http://doi.org/10.21009/AKSIS 